\title{
Configurações
}

Revista de sociologia

\section{As cores da investigação em Portugal: África, identidade e memória*}

The complexion of research in Portugal: Africa, Identity and Memory

Les couleurs de la recherche au Portugal : Afrique, identités et mémoire

\section{Sheila Khan}

\section{OpenEdition}

\section{Journals}

Edição electrónica

URL: http://journals.openedition.org/configuracoes/3282

DOI: $10.4000 /$ configuracoes.3282

ISSN: $2182-7419$

\section{Editora}

Centro de Investigação em Ciências Sociais

Edição impressa

Data de publição: 27 Junho 2016

Paginação: 43-56

ISSN: 1646-5075

\section{Refêrencia eletrónica}

Sheila Khan, « As cores da investigação em Portugal: África, identidade e memória* », Configurações [Online], 17 | 2016, posto online no dia 30 junho 2016, consultado o 01 maio 2019. URL : http:// journals.openedition.org/configuracoes/3282 ; DOI : 10.4000/configuracoes.3282 
Khan, Sheila - As cores da investigação em Portugal: África, identidade e memória.

Configurações, vol. 17, 2016, pp. 43-56

\title{
As cores da investigação em Portugal: África, identidade e memória*
}

\author{
SHEILA KHAN** \\ Centro Interdisciplinar de Ciências Sociais - Polo Universidade do Minho
}

\begin{abstract}
Resumo
O presente artigo pretende analisar o impacto social e cultural da investigação sobre o que tradicionalmente é denominado por Estudos Africanos. Paralelamente, este trabalho procura refletir sobre a maturidade dos estudos africanos no contexto português de investigação, tendo em conta que no ano de 2015 se celebraram os 40 anos de independência das muitas ex-colónias portuguesas com todo o seu património de memórias e (pós-)memórias intelectualmente partilhadas. Para além deste propósito, procura-se pensar o posicionamento do investigador no tempo e espaço de um paradigma que divide o pensamento científico entre Norte Global e Sul Global.
\end{abstract}

Palavras-chave: investigação, África, identidade, memória, Estudos Africanos.

\begin{abstract}
The complexion of research in Portugal: Africa, Identity and Memory

This article analyzes the social and cultural impact of research carried on within what is traditionally referred to as African studies. Moreover, this paper seeks to reflect on the maturity of African studies in the Portuguese context, given that in 2015 we have celebrated 40 years of independence of many former Portuguese colonies with all their heritage of memories and intellectually shared post-memories. Finally, we discuss the positioning of the researcher within the time and space of a paradigm that divides scientific thought between the Global North and Global South.
\end{abstract}

Keywords: research, Africa, identity, memory, African Studies.

\footnotetext{
* Este texto resulta de um projeto de pós-doutoramento sob o tema O Conhecimento nas Relações 'Norte-Sul': O Contexto Societal e de Investigação em Portugal, em realização no Centro Interdisciplinar em Ciências Sociais (CICS.NOVA.UMinho).

* Investigadora no Centro Interdisciplinar de Ciências Sociais - Polo Universidade do Minho. Email: sheilakhan31@gmail.com.
} 


\section{Résumé \\ Les couleurs de la recherche au Portugal: Afrique, identités et mémoire}

Cet article analyse l'impact social et culturel de la recherche sur ce qu'on appelle traditionnellement les Études africaines. Ce texte vise une réflexion sur la maturité des études africaines dans le contexte portugais de la recherche, sachant qu'on a célébré en 2015 les 40 ans d'indépendance des nombreuses anciennes colonies, avec tout leur patrimoine de mémoire et de (post) mémoire intellectuellement partagés. Outre ce propos, nous avons cherché à réfléchir sur le positionnement du chercheur dans le temps et l'espace d'un paradigme qui divise la pensée scientifique entre le Nord Global et le Sud Global.

Mots-clés : recherche, Afrique, identité, mémoire, Études Africaines.

Todavia, pelo menos uma outra questão se coloca: quão africanos são os chamados estudos africanos? Por exemplo, por história africana entende-se normalmente o discurso histórico sobre África e não necessariamente um discurso histórico proveniente de África ou produzido por africanos.

Paulin J. Hountondji, 2008: 149

\section{Introdução}

Este ano várias das ex-colónias portuguesas atingiram a maturidade histórica de quarenta anos de independência política face ao longo regime colonial e imperial português. As celebrações em torno dos vários países de maioridade política já alcançada foram abundantes quer ao nível político e diplomático, quer ao nível intelectual e as atividades organizadas à volta desta profunda relação histórica e humana entre Portugal, Angola, Cabo Verde, GuinéBissau, Moçambique e São Tomé e Príncipe são um testemunho dessa relação. As embaixadas destes países africanos de língua portuguesa dedicaram-se a organizar com cuidado e gosto pelas 'cores' das suas bandeiras independentes vários eventos, evocando e reivindicando para todos os seus cidadãos nacionais no país e na diáspora a força e o orgulho associados às suas independências. As universidades portuguesas expressaram com a organização de conferências, seminários, congressos nacionais e internacionais este momento de exaltação histórica, mas também quiseram ir mais longe fazendo destes encontros um momento de um balanço reflexivo sobre o passado e suas mutações para dentro deste presente conturbado não apenas em alguns destes países africanos mas na sua relação com o mundo global. Embora a energia das comemorações académicas se tenha concentrado mais na capital do país, Lisboa, e no Porto, importa realçar que outros pontos do país quiseram acompanhar estas datas comemorativas e pensar não somente a Europa no mundo, mas África 
no mundo no espaço de um tempo em crise e com novas mutações identitárias e geopolíticas ${ }^{1}$.

Tudo parece normal e quase comum pela partilha longa e inevitável que, aparentemente, temos construído com estes países e com as gentes destes países. $\mathrm{Na}$ verdade, os patrimónios de influência portuguesa no mundo não se podem descartar nem sequer ignorar (Ribeiro e Rosa, 2015). Contudo, grande estupefação surge quando no ano de 2015 temos uma nova e inédita ministra da Justiça. A questão não é a ministra ser mulher, a grande surpresa é que esta ministra é uma mulher negra! Francisca Van Dunem, e como alguns alcunham como luso-angolana, é negra, e rompe pela primeira vez com o racismo graciosamente chamado de subtil e rompe-o de uma forma grupal, porque o nosso primeiro-ministro António Costa é de origem goesa e um dos secretários de Estado, Carlos Miguel, deste nosso governo atual é neto de ciganos. Finalmente, um governo étnico e multicultural, dizem as vozes mais otimistas!

Mas a estupefação não termina aqui, alcança algo que me parece relevante e surpreendente e que Bárbara Reis, jornalista e diretora do Jornal Público, explora bem no seu artigo "De que cor é esta ministra?", ao alertar para o seguinte:

Não vale a pena fazer uma festa. Nem António Costa, nem Francisca Van Dunem, nem Carlos Miguel são a prova de que somos um país cosmopolita e multicultural, onde as minorias étnicas vivem integradas e com igual acesso à educação e ao mercado de trabalho.

Mas o extremo oposto é igualmente ridículo. Não faz sentido fazer de conta que não reparámos que Van Dunem é negra. Não notar que a ministra é negra seria o mesmo que dizer que em Portugal estamos tão habituados a ver negros em cargos de poder que já nem reparamos. E isso não é verdade. Todos notámos. (Reis, Público, 29-11-2015)

Parece-me importante colocar o dedo na ferida e partir para o propósito deste artigo que é criticamente pensar na inexistência de uma tradição de estudos sobre grupos étnicos e grupos africanos em Portugal quando temos um percurso longo de relações coloniais e pós-coloniais com as pessoas que vieram do antigo Ultramar e, acima de tudo, na ausência de uma investigação-ação que possa promover um impacto palpável e visível da investigação no espaço e vida destas pessoas.

1 Realço a organização de uma conferência internacional organizada na Universidade do Minho, $A$ Europa no Mundo, o Mundo na Europa. Crise e Identidade (18 e 19 de Junho, 2015), organizado por Sheila Khan (CICS.NOVA.UMinho), Rita Ribeiro (CECS, Universidade do Minho) e Vítor Sousa (CECS, Universidade do Minho), e que contou com a presença de colegas da Guiné-Bissau e, nomeadamente, com a presença da RDP-África e colaboradores do programa Debate Africano. 


\section{Estudos Africanos : África, memória e identidade}

Nos últimos anos coloca-se nos estudos coloniais e pós-coloniais de língua portuguesa a ênfase na memória das experiências daqueles que vieram do antigo Ultramar. Se os estudos literários empurraram para a luz do dia, ficcionalmente, os sentidos de vida e de identidade dos percursos daqueles que viveram África e que de lá saíram de uma forma voluntária ou involuntária (Cardoso, 2011), outras experiências autobiográficas também ajudam a descascar a ideia mítica de um colonialismo simpático e luso-tropical (Figueiredo, 2015; Vieira, 2015). Não obstante os contributos de natureza literária e culturalista, e sem esquecer os contextos políticos e relações diplomáticas vigentes entre o país ex-colonizador e os países ex-colonizados, a tradição de estudos sobre grupos étnicos ou grupos africanos está longe de assumir o estatuto de maioridade em termos de investigação. Não desmerecendo trabalhos de investigação sobre africanos e mesmo etnias ciganas por sociólogos, antropólogos, historiadores e psicólogos sociais, a investigação limita-se muito a um diálogo entre e para os pares. Sendo certo que esta crítica não almeja desmerecer nenhum trabalho em específico, muitas vezes embalamo-nos numa linguagem fechada, armadilhada e rodeados de instrumentos que a normalidade das pessoas desconhece ou não entende. Diria até que, apesar da seriedade dos estudos realizados, a falta de realidade etnográfica está às vezes ausente. Num artigo de Jorge Vala e Marcus Lima sobre diferenciação cultural e racismo em Portugal entre grupos 'brancos' e africanos os autores dizem:

No estudo realizado em Portugal mostra-se que a perceção de diferenças culturais não é uma descrição neutra de diferenças, mas uma avaliação negativa da diferença, e que, quanto maior é a diferença percebida entre brancos e negros, maior é a orientação para a discriminação dos negros nas políticas sociais e para a restrição dos direitos sociais e de cidadania política dos imigrantes negros. (Vala e Lima, 2002: 182)

Lendo com atenção este pequeno excerto do artigo em análise, as perguntas que logo saltam são: de quem estamos a falar? Que negros são estes? E que tipo de negros queremos nós que sejam os nossos sujeitos que possam validar as nossas teorias e metodologias? Portugal é um país de gerações de africanos que muito pouco têm já do que poderíamos chamar de africanidade. Em segundo lugar, ao colocarmos sempre a ênfase de que somos um país pós-colonial, multicultural e com pendor para um Norte Global, temos a tentação de esmagar aquilo que é nosso, que é incontornavelmente endógeno, porque estes 'negros' são nossos vizinhos, são nossos colegas de trabalho, formados e civilizados de acordo com uma cultura de timbre ocidental. Em terceiro lugar, o pós-colonial português não pode apagar da sua historicidade a cadeia de diferenças culturais de que somos feitos e de que resultou de uma certa forma a manutenção e a sobrevivência do colonialismo ultramarino. 
Certamente que o racismo está entre nós e não é, como advogam alguns estudiosos, um racismo subtil (Vala, 1999), é um racismo hibernado em tempos passados, é um racismo de memória (Henriques, 2015, 2016) e, acima de tudo, é um racismo identitário porque temos a tendência de cotejar as nossas experiências e o modo como criámos as nossas narrativas de uma forma hierárquica com outros que percecionamos como inferiores e menos civilizados do que o 'nós'. A herança colonial e pós-colonial portuguesa não se descola assim tão facilmente seja daqueles que vivem no mundo dos comuns dos mortais, seja daqueles que trabalham e operam no mundo das ideias e das teorias. $\mathrm{Na}$ verdade, investigação mais recente indica a existência de dois mundos: por um lado, um pós-colonialismo do quotidiano e, por outro lado, um pós-colonialismo de reflexão, mais académico (Khan, 2015).

$\mathrm{O}$ mundo do pensamento académico pode ter a vantagem de pensar por meio de ferramentas mais sustentáveis que nos permitem averiguar e auscultar com maior segurança as nossas realidades sociais, mas nada é mais humano do que sermos capazes de estar e viver no lugar do Outro, daqueles que sem os nossos recursos conseguem também pensar e construir a sua visão do mundo. De facto, nós precisamos como investigadores desse manancial que ultrapassa a nossa forma de ser e de estar, que não faz parte da nossa formação cultural e intelectual, que não usa a mesma linguagem e os mesmos utensílios sociais para conseguirmos os nossos objetivos: investigar, analisar, escrever artigos, publicar artigos para encaixilharmos nos nossos currículos as metas atingidas, na maioria das vezes, de acordo com agendas de financiamento austeras, pouco tolerantes e implacáveis no que toca o tempo de reflexão e de seleção de dados para a realização de um trabalho de investigação sólido, comprometido com a realidade e com impacto nessa mesma realidade de que fazem parte muitos dos dados usados para a concretização destes objetivos.

Como investigadores permanecemos arreigados aos nossos universos culturais perdendo de vista o conhecimento local, idiossincrático dos grupos humanos que estudamos. Durante este ano encontra-se a decorrer uma exposição com múltiplas formas de expressão artísticas onde se inclui a arte, a literatura, a história, a antropologia e a política em torno dos 40 anos do movimento de retorno das ex-colónias portuguesas: Retornar - Traços de Memória. Comissariada pela antropóloga Elsa Peralta, este trabalho vale pela sua relação histórica e cronológica com os 40 anos da independência das ex-colónias portuguesas. No entanto, a questão que como investigadora eu gostaria de colocar é a seguinte: para quem está destinada esta exposição? Certamente que é tempo de se abrirem as comportas da memória histórica e pública deste país, que é de uma enorme importância a partilha de testemunhos e, com sorte, teremos ainda vivas muitas das pessoas que sentiram na pele todo o processo do retorno, embora, para muitas dessas pessoas, é importante dizê-lo, este movimento não significou o retornar a um lugar mas, pelo contrário, representou 
com alguma amargura e sentido de exílio chegar a um lugar desconhecido e inóspito (Figueiredo, 2015; Cardoso, 2011; Gomes, 2011;Khan, 2006). Ao mesmo tempo, este esforço vale a possibilidade de dar às novas gerações o sentido de história e de conhecimento sobre o passado dos seus familiares e o seu e o presente em que vivem. Mas, mantenho-me colada à minha pergunta: quem são os protagonistas desta exposição? De acordo com o site onde se encontra delineada o corpus desta exposição, os convidados para dialogar-se à volta do retorno são: escritores, ensaístas e académicos. Então, onde ficam as pessoas que retornaram? Não é importante escutá-las em primeira mão? Não é relevante para a memória histórica de um país dar a conhecer-se as suas histórias menos oficiais mas não menos importantes para a sua própria historicidade? Por que não a criação de mesas-redondas, de encontros com essas pessoas? Onde está a importância da memória e da pós-memória de uma maneira mais ampla, mais acessível e menos elitista? Estamos preparados para escutar e estudar o Outro, quando o Outro também somos nós? Para que servem estas celebrações das independências africanas quando estamos surpreendidos com o facto de termos uma ministra negra, um primeiro-ministro goês e um secretário de Estado de origem cigana? Em que medida a investigação teve e tem um papel para esclarecer as pessoas, relativizar as suas memórias e as suas crenças de que o Outro é tão semelhante, porque esteve connosco durante todo o caminho que foi a construção, a manutenção e desmantelamento do império?

Não se esgotaram as perguntas, mas acredito que são já um número suficiente para percebemos que as ausências não são apenas construídas ou mantidas por circunstâncias sociais, políticas e económicas. Como investigadores temos o dever e a responsabilidade social de recusar estas ausências, de minorar distâncias entre o sujeito que investiga e o objeto ou o sujeito que são avaliados; de democratizar a memória de uns e de outros e aproximá-las num tempo de um diálogo, de uma partilha onde não existam espaços de antenas mais ou menos privilegiados, que existam espaços humanos de escuta e de reflexão coletiva. Nesta perspetiva concordo com o ensaísta e investigador António Pinto Ribeiro que numa crónica intitulada "Retornados, refugiados, deslocados e colonialismo português" e sobre o conjunto de iniciativas sobre as memórias dos muitos retornos, observa que:

Abordar a questão dos retornados só depois de terem passado 40 anos sobre o acontecimento pode parecer estranho, não fora o caso de esta questão estar associada a uma outra sobre a qual se produziu uma amnésia que se teima em não tratar. Trata-se do colonialismo português. Não é possível abordar seriamente a questão dos retornados enquanto não se realizar um livro negro do colonialismo como o fizeram outros países ex-colonizadores e, em consequência disso, não se tratar do tema - que é um problema da História mas também da Literatura e dos Estudos Culturais - e não se produzirem narrativas disseminadas e acolhidas pelo sistema de aprendizagem escolar e de formação dos cidadãos. Na criação das 
narrativas sobre o colonialismo e suas consequências, cujo problema histórico é o retorno maciço das ex-colónias, é crucial contrapor as narrativas quer dos ex-colonizados, quer dos cidadãos residentes em Portugal, que foram os anfitriões dos retornados, quer ainda, e necessariamente, dos cidadãos das ex-colónias que assistiram à partida desses mesmos retornados. (Ribeiro, 2015: 28)

Concordo com os dois argumentos aduzidos no excerto apresentado: por um lado, a importância de estas narrativas serem acolhidas e transmitidas pelo sistema de aprendizagem escolar, nomeadamente, pelos manuais escolares (Araújo e Maeso, 2010, 2011, 2013, 2015; Cabecinhas e Feijó, 2010, 2013); e, por outro lado, a relevância de contrapor narrativas seja dos retornados, seja daqueles que também vieram no tempo do processo do retorno, os africanos ex-colonizados (Khan, 2015). O perigo de uma só narrativa que tudo explica e tudo abarca permanece em muitos momentos no modo até como pensámos e investigamos o retorno desses Outros que fomos catalogando como retornados, e uma narrativa que continua por estudar; é que não existem como o nome da exposição informa 'Traços de memória', existem muitos traços de memórias algumas por explorar, outras ainda silenciosas e muitas mais por descobrir. Como observa o historiador Alon Confino a memória histórica de uma sociedade incorpora dinâmicas muito próprias e que expressam muita da maturidade, partilha e relações de poder e de autorrepresentação dessa sociedade e dos seus grupos sociais, no sentido em que:

(...) in the history of memory is not how a past is represented but why it was received or rejected. For every society sets up images of the past. Yet to make a difference in a society, i tis not enough for a certain past to be selected. It must steer emotions, motivate people to act, be received; in short, it must become a socio-cultural mode of action. Why is it that some pasts triumph while others fail? Why do people prefer one image of the past over another? (Confino, 1997: 1390)

Esta questão relacionada com a hierarquização das memórias é complexa e levanta reflexões não só de cariz político e ideológico; urge também pensar em que medida a investigação, em todo o seu processo de seleção dos seus objetos de estudo, no uso de certas teorias em detrimento de outras e na aplicação de determinadas metodologias, não está também permeável a este tabuleiro de relações de poder que têm indubitavelmente influência na forma como fazemos investigação e as metas que idealizamos. Tem sido quase comum atribuir um mea culpa às pressões de financiamento e aos condicionamentos que esta manipulação traz para a escolha de um projeto de investigação e ao modo como devemos apresentá-lo. Mas, não é espúrio e parece-me um estudo a ser feito que os investigadores também são portadores de uma determinada memória histórica e coletiva onde foram educados, formados e formatados de acordo com uma ritualização social, cultural e intelectual. Na minha opinião, 
descurar esta influência sobre os nossos percursos de investigação pode conduzir-nos a uma grande ingenuidade face ao modo como nos relacionamos com os nossos trabalhos, com as nossas investigações e como conduzimos essas mesmas investigações. Os investigadores não são apenas aquilo que investigam e como investigam, os investigadores como seres humanos e cidadãos adaptam-se às circunstâncias, aos condicionamentos e de uma certa maneira a uma determinada postura cultural que teoricamente defendem nas suas reflexões, ensaios, palestras, mas que na vida prática não se coaduna como o modus vivendi de cada um. Isto significa dizer que, embora o interesse em estudar os grupos étnicos ou grupos africanos assuma já uma presença incontestável nas nossas universidades e carreiras universitárias, o cariz de uma tradição e de um compromisso entre realidade e estudo está longe de ser verdade e uma conquista no contexto de investigação português.

Parafraseando a jornalista Bárbara Reis e evocando o seu artigo sobre a nomeação de uma mulher negra como ministra (2015), não é por termos entre nós estudos e trabalhos já publicados sobre os africanos e os chamados grupos étnicos que podemos celebrar entre nós uma tradição de Estudos Africanos. Não podemos esquecer que muitas vezes os investigadores recorrem a teorias, conceitos e metodologias cujo impacto na vida daqueles que são investigados é nulo e inexistente, ficando estes trabalhos mais à mercê de uma legitimação e análise crítica dos pares do que propriamente daqueles que serviram de material de trabalho para validar o armamento teórico e metodológico de que nos servimos como 'Quixotes de la Mancha' da investigação em 'Estudos Africanos'.

\section{Os estudos africanos no contexto pós-colonial português}

Paulin Hountondji expressa, na minha opinião, um grande e não menos problemático e incómodo questionamento sobre a veracidade ou maturidade dos Estudos Africanos no contexto ocidental, e ocidentalizado, de investigação, com a seguinte pergunta: "em que medida são africanos os chamados Estudos Africanos?" (itálico meu, Hountondji, 2008: 149). Dentro do seu pensamento torna-se claro o argumento de que a produção intelectual e académica sobre África é produzida e interpretada segundo critérios de pensamento e de práxis de cariz ocidental, e mais do que construir uma visão do mundo que incorpore os elementos sociais, culturais, ontológicos dos sujeitos e objetos que se pretende pesquisar, procura-se 'arrancar' verdades e explicações que, por vezes, não vão ao encontro das realidades específicas daqueles que servem como elementos de pesquisa, de projetos e de textos para publicação. Como salienta o autor, este conhecimento sobre África é um conhecimento 'extravertido’ porque criado para servir interesses exógenos e não propriamente para acolher, integrar e expressar genuinamente as reais vivências e visões dos sujeitos estudados. Com efeito, a linguagem conceptual e teórica que usamos 
para falar com a realidade não serve como elemento de aproximação e de inclusão no universo do Outro. Pode, certamente, existir um cuidado e uma forma de comportamento dúctil e gentil para podermos sem falsidade conquistar a confiança daquele que pretendemos estudar, perceber e até desafiar, e esta é a relação ideal da investigação com a sociedade: a de uma relação de saber, de ética e de transparência. No entanto, vamos para as realidades sociais convictos de que já chegámos lá ainda antes de entrarmos em campo, ainda mesmo de nos confrontarmos com realidades que estão mesmo ali ao nosso alcance, mas que, na verdade, são realidades diferentes das nossas pelos percursos sociais, culturais e históricos dos sujeitos a pesquisar. E que devem ser tratadas com o respeito por essa diferença cultural, para não cairmos no vazio da "história única".

No contexto português de investigação esta preocupação está bem presente quando olhamos para a leitura pós-colonial de algumas narrativas produzidas sobre africanos e retornados. Permanece, ainda, uma certa flacidez na relação entre o mundo académico e de reflexão e o seu diálogo com as comunidades africanas residentes em Portugal (Khan, 2006, 2015), flacidez que se torna legível no modo como as pessoas destas comunidades se sentem sub-representadas nos trabalhos académicos baseados sobre estas comunidades e não para estas comunidades ou pessoas. Embora os esforços de muitos investigadores sejam significativos, estes esforços estão longe de mapear e de sustentar um lugar de tradição de estudos que podemos, com segurança, denominar como Estudos Africanos. Paulo de Medeiros observa, no texto de reflexão No fio da navalha, esta urgência de abrangência para melhor pensar e criticamente compreender África e os estudos sobre as comunidades africanas, expressando o seu pensamento deste modo:

Escrever hoje em dia tornou-se mais do que banal. Exceto que fazê-lo bem e com um sentido definido nunca o será. A escrita pode ter muitas funções ou até mesmo nenhuma em especial. Tal como qualquer outro modo de representação a escrita por si mesma nada garante. Mas enquanto veículo privilegiado do pensamento continuará a ocupar um lugar de primazia no horizonte intelectual. Se pensar Portugal sempre foi apanágio de uma certa elite cultural e burguesa, fechada sobre si, restrita e homogénea, hoje em dia pensar Portugal, isto é, refletir sobre a ideia de comunidade com esse nome, tem de ser uma tarefa desdobrada e múltipla, aberta a todos os tipos de vozes. (Medeiros, 2015: 7)

É precisamente este desdobramento e abertura para outras narrativas que importa incorporar nos estudos africanos no contexto português de investigação, porque ainda permanece uma tendência muito eurocêntrica em olhar de dentro para fora, com um pendor obsessivo em incorporar e despir o Outro das suas diferenças e linguagens, para poder colar-se nessas realidades as nossas teorias e visões do mundo ao objeto de trabalho. Parece rebarbativa esta 
minha posição, mas esta preocupação já não é uma angústia solitária, e a vontade de chegar até às comunidades africanas em Portugal não como objetos de trabalho, mas como interlocutores e produtores de 'teorias' e de 'conceitos' capazes de indicar novos caminhos e pistas de investigação, é já algo concreto e audível nas reflexões de outros investigadores. Num estudo realizado sobre a pós-colonialidade portuguesa (Khan, 2015), Rosa Cabecinhas, investigadora em estudos pós-coloniais de língua portuguesa, responde à seguinte questão: o pós-colonialismo de reflexão/académico consegue retratar o quotidiano do pós-colonialismo português?

Acho que não, espelha pouco. Acho que, às vezes, há esse divórcio entre a comunidade académica e os investigadores e, posso dizer, o senso comum, estou a querer dizer as pessoas no seu dia-a-dia, no seu quotidiano. E, muitas vezes, os investigadores envolvem-se em reflexões e não consultam ou não interrogam, suficientemente, os outros, para terem em conta os elementos de reflexão, que podem ser algo dissonantes face aos paradigmas estabelecidos. (Khan, 2015: 78)

É este divórcio flagrante que, mais do que preocupante para os Estudos Africanos, reflete de uma maneira muito clara o excesso da memória histórica e a relação entre memória histórica de uma sociedade e os estudos da memória nela produzidos, validados e outros tantos silenciados (Martins, 2015). Porque não é só a relação e a visão de Portugal sobre as comunidades africanas aqui residentes que importa, é também necessário o estudo do 'outro lado da linha', a visão, representação e leitura destas comunidades sobre Portugal. Hoje pensar a questão dos africanos e dos retornados no espaço e tempo de um pós-colonialismo português levanta muitas questões e cuidados com o modo como pesquisamos estes conceitos humanos: o que é ser africano e retornado após a descolonização das colónias portuguesas? O que pensam estes africanos e retornados de Portugal e da sociedade portuguesa em geral? Estas pessoas sentem-se como testemunhas e sujeitos de uma autoridade de memória, num tempo de revisão sobre o passado e sobre os 40 anos da independência das ex-colónias? Está a sociedade portuguesa preparada para acolher as suas narrativas (Ribeiro, 2010)? A investigação comprometida com estas questões poderá a seu tempo responder com propriedade a estas pistas, contudo, torna-se importante deixar aqui a reflexão de Inocência Mata, a investigadora em literaturas africanas de expressão portuguesa e de estudos pós-coloniais, quando afirma que é prioritário perceber:

que o povo português nunca aprendeu a lidar com o Outro, e essa aprendizagem é uma aprendizagem que tem trinta anos, não se esqueça que o colonialismo português foi um colonialismo assimilacionista. É um colonialismo em que o Outro só se integrava na sociedade portuguesa se fosse igual ao metropolitano. E, mesmo sendo igual, dependia do lugar onde ele nasceu, porque havia branco de 
segunda, agora imagine o preto. É preciso, também, quando nós escalpelizamos as questões, ter em conta determinadas realidades. A realidade é que o povo português nunca aprendeu a lidar com a diferença, essa aprendizagem é uma aprendizagem que tem trinta anos. Nesta perspetiva, ele é um bom aluno (...), sobretudo, para quem está em Portugal há vinte anos como eu, é possível ver-se como as relações mudaram, houve mudança... A independência das colónias foi há trinta e tal anos, (...), e não foi em situação de democracia. (Khan, 2015: 63)

Quando lanço a questão sobre se as pessoas das comunidades africanas se sentem representadas e, de um certo modo, se acreditam que estes estudos e pesquisas são realizados para elas e não sobre elas, a resposta traduz a realidade separada e desfasada desse pós-colonialismo do quotidiano e o pós-colonialismo académico (Khan, 2015) e que demonstra o longo caminho que temos a percorrer, um caminho que, nas palavras de Paulo de Medeiros, denuncia que "muito resta ainda por fazer para se compreender como a condição pós-colonial é vivida no quotidiano português e não simplesmente concebida nos modelos teóricos de investigadores" (Medeiros, 2015: 8).

É este salto que a investigação sobre Estudos Africanos no contexto português está para dar, um salto que, na minha opinião, o jornalismo de investigação já conseguiu e concretizou pela sua linguagem, pelos conceitos e modos de chegar a outras narrativas, corrigindo pela lógica da sua forma de pensamento e de comunicação o perigo da narrativa única, mostrando que não há traços de memória, mas muitos e diferentes e multilocalizados traços de memórias para se perceber a historicidade de Portugal e a dos países que, hoje, podem celebrar os seus 40 anos de independência política. Refiro-me ao trabalho de Joana Gorjão Henriques, jornalista do jornal Público, que tem vindo a desenvolver uma série especial com o tema: Racismo em português (em 2015 sobre Angola, GuinéBissau, e em 2016 sobre Cabo Verde, São Tomé e Príncipe e Moçambique), nos vários países onde o colonialismo português imperou e impera nas suas variadas e complexas versões e heranças culturais, sociais e identitárias: heranças de experiências e de memórias entre gerações. É um trabalho de uma grande propriedade e com a virtude de trazer para o espaço do debate público a leitura e a constatação de duas observações: por um lado, não é mais possível sonegar da nossa memória histórica que outras narrativas e outras visões do mundo são dela uma parte significativa para, nos dias de hoje, se perceber o que é estudar o colonialismo e o pós-colonialismo e os estudos africanos de expressão portuguesa; e, por outro lado, como investigadores devemos admitir que os nossos trabalhos não devem ser feitos para os pares, para uma elite intelectual, para a validação dos nossos anseios e metas de investigação.

Pelo contrário, o nosso trabalho e compromisso ético tem de basear e nortear-se no sentido de um reconhecimento efetivo e não apenas teórico da diversidade da experiência humana daqueles que mais do que sujeitos de 
observação são também eles sujeitos produtores de conhecimento e de reflexão: testemunhas e testemunhos de histórias que a História oficial dos países ex-colonizados e do país ex-colonizador não conseguiu ainda acolher e com a serenidade possível aceitar, e sem pudor pensar com justiça histórica essas outras narrativas e experiências (Henriques, 2016).

\section{Considerações (finais)}

Apesar do caminho de investigação já percorrido sobre as independências políticas das colónias africanas e o processo de descolonização e do retorno, a maturidade que poderíamos evocar e celebrar relativa aos estudos africanos ainda permanece num estágio de consolidação. Não basta apenas apresentar dados estatísticos e ratings de publicação, o mais relevante é criticamente sopesar o lugar e a relevância destes estudos no que concerne aos sujeitos da experiência colonial e pós-colonial africana. Os sujeitos desta experiência são muitos e com uma multiplicidade inesgotável de formas de estar, de ser e de pertença que os nossos modelos teóricos e metodológicos ainda embutidos numa visão eurocêntrica não vão alcançar e nem perceber, porque é preciso saltar o muro, olhar para além do 'quintal' das nossas representações sociais, culturais e históricas. Torna-se cada vez mais premente olhar para além das políticas de memória histórica de uma sociedade que, ainda, escreve a narrativa dos Outros de acordo com critérios externos e muitas vezes descontextualizados das suas visões do mundo. A influência da memória histórica em cada um de nós como cidadãos, como investigadores, não pode ser ignorada nem sequer ser romantizada em convicções pueris de que somos seres menos impuros e capazes de realizar os nossos trabalhos sem qualquer tipo de permeabilidade social, cultural e histórica. Isto é uma falácia e uma fantasia perigosa para quem investiga. Uma visão de investigação sobre africanos - e não para africanos - traduz-se neste tipo de observação:

No estudo realizado em Portugal mostra-se que a perceção de diferenças culturais não é uma descrição neutra de diferenças, mas uma avaliação negativa da diferença, e que, quanto maior é a diferença percebida entre brancos e negros, maior é a orientação para a discriminação dos negros nas políticas sociais e para a restrição dos direitos sociais e de cidadania política dos imigrantes negros. (Vala e Lima, 2002: 182)

Uma leitura e uma análise da realidade com africanos, pelo contrário, é bem diferente e mostra-nos o défice de representação e de visibilidade que estes sujeitos sentem no contexto de investigação em Estudos Africanos em Portugal, o divórcio entre mundo académico e o seu mundo vivencial: 
Eu acho que não. Quer dizer, eu não estou a dizer que as pessoas não estejam interessadas em tentar perceber. Mas, o que eu me apercebo, o que eu sinto é que fica só no papel. É tudo muito bonito estarmos a ler, muito giro, mas, na prática, eu não vejo essas coisas. (Khan, 2015: 80)

Eu nunca fui abordada por ninguém (...). Se existe, se há alguma coisa, eu não tenho conhecimento; eu não tenho conhecimento de alguma instituição que se tenha preocupado em saber como é que os moçambicanos vivem aqui, em Portugal. (Ibidem, 2015: 80)

\section{Referências}

ARAÚJO, Marta; MAESO, Silvia (2010), "Explorando o eurocentrismo nos manuais portugueses de História”. Estudos de Sociologia, 15 (28): 239-270.

ARAÚJO, Marta; MAESO, Sílvia (2011), "Institucionalização do silêncio: A escravatura nos manuais de história portugueses”. Revista/Ensino Superior, Revista SNESup, 39: 1-10.

ARAÚJO, Marta; MAESO, Sílvia (2013), “A presença ausente do racial: discursos políticos e pedagógicos sobre História, 'Portugal' e (pós-colonialismo)”. Educar em Revista, 47: 145-171.

ARAÚJO, Marta; MAESO, Sílvia (2015), The Contours of Eurocentrism: Race, History, and Political Texts. Lanham, MD: Lexington Books.

CABECINHAS, Rosa; FEIJÓ, João (2013), "Representações sociais do processo colonial Perspetivas cruzadas entre estudantes moçambicanos e portugueses”. Revista Configurações, 12: 117-139.

CABECINHAS, Rosa; FEIJÓ, João (2010), "Collective memories of Portuguese colonial action in Africa: Representations of the colonial past among Mozambicans and Portuguese youth". International Journal of Conflict and Violence, 4 (1): 28-44.

CARDOSO, Dulce Maria (2011), O Retorno. Lisboa: Tinta da China.

CONFINO, Alon (1997), "Collective Memory and Cultural History: Problems of Method". The American Historical Review, 102 (5): 1386-1403.

FIGUEIREDO, Isabela (2015), Caderno de memórias coloniais. Lisboa: Caminho.

GOMES, Aida (2011), Os Pretos de Pousaflores. Lisboa: Dom Quixote.

HENRIQUES, Joana Gorjão (2015), “Série Especial: Racismo em Português - Angola”, Público, Novembro.

HENRIQUES, Joana Gorjão (2015), “Série Especial: Racismo em Português - Guiné-Bissau”, Público, Dezembro.

HENRIQUES, Joana Gorjão (2016), “Série Especial: Racismo em Português - Cabo Verde”, Público, Janeiro.

HOUNTONDJI, Paulin J. (2008), “Conhecimento de África, conhecimento de Africanos: Duas perspetivas sobre Estudos Africanos”. Revista Crítica em Ciências Sociais, 80: 149-160.

KHAN, Sheila (2006), "Identidades sem chão. Imigrantes afro-moçambicanos: Narrativas de vida e de identidade, e perceções de um Portugal pós-colonial”. Luso-Brazilian Review, 43 (2): 1-26.

KHAN, Sheila. (2015), Portugal a Lápis de Cor. A Sul de uma pós-colonialidade. Coimbra: Almedina.

MARTINS, Bruno Sena (2015), "Violência colonial e testemunho: Para uma memoria pós-abissal”. Revista Crítica em Ciências Sociais, 106: 105-126.

MEDEIROS, Paulo de (2015), "No Fio da navalha", in Sheila Khan, Portugal a Lápis de Cor: A Sul de uma pós-colonialidade. Coimbra: Almedina: 7-13. 
REIS, Bárbara (2015), “De que cor é esta ministra?”, Público, 29 de Novembro.

RIBEIRO, António Pinto (2015), "Retornados, refugiados, deslocados e colonialismo português”, Público, 21 de Dezembro.

RIBEIRO, António Sousa (2010), “Memória, identidade e representação: Os limites da teoria e a construção do testemunho". Revista Crítica em Ciências Sociais, 88: 9-21.

RIBEIRO, Margarida Calafate; ROSSA, Walter (2015), "Entrevista com Eduardo Lourenço", in Margarida Calafate Ribeiro e Walter Rossa (org.), Patrimónios de Influência Portuguesa: modos de olhar. Lisboa: Fundação Calouste Gulbenkian, 149-170.

VALA, Jorge (ed.) (1999), Novos racismos: Perspectivas comparativas. Oeiras: Celta.

VALA, Jorge; LIMA, Marcus (2002), “Individualismo meritocrático, diferenciação cultural e racismo". Análise Social, XXXVII: 181-207.

VIEIRA, José Luandino (2015), Papéis da prisão. Lisboa: Caminho.

Submetido: 03-01-2016

Aceite: 01-03-2016 